December 2020

\title{
Equity, Diversity, and Inclusion Climate Assessment Activities: Development and Strategic Use in Diversity Action Plans
}

\author{
Dr. Kristen M. Radsliff Rebmann \\ SJSU School of Information, kristenrebmann@gmail.com \\ Parinaz Zartoshty \\ SJSU International Student \& Scholar Services, parinaz.zartoshty@sjsu.edu \\ Kim Green \\ SJSU International Gateways, kim.green@sjsu.edu \\ Erin Kelly-Weber \\ SJSU Study Abroad \& Away, erin.kelly-weber@sjsu.edu \\ Dr. Vidalino Raatior \\ SJSU Study Abroad \& Away, vid.raatior@sjsu.edu \\ Follow this and additional works at: https://scholarworks.sjsu.edu/ischoolsrj \\ See next page for additional authors \\ Part of the Bilingual, Multilingual, and Multicultural Education Commons, Disability and Equity in \\ Education Commons, Educational Administration and Supervision Commons, Information Literacy \\ Commons, Leadership Studies Commons, Online and Distance Education Commons, Organization \\ Development Commons, Social Justice Commons, and the University Extension Commons
}

\section{Recommended Citation}

Radsliff Rebmann, D. M., Zartoshty, P., Green, K., Kelly-Weber, E., Raatior, D., \& Vonderach, L. (2020). Equity, Diversity, and Inclusion Climate Assessment Activities: Development and Strategic Use in Diversity Action Plans. School of Information Student Research Journal, 10(2). https://doi.org/10.31979/

2575-2499.100202 Retrieved from https://scholarworks.sjsu.edu/ischoolsrj/vol10/iss2/2

This article is brought to you by the open access Journals at SJSU ScholarWorks. It has been accepted for inclusion in School of Information Student Research Journal by an authorized administrator of SJSU ScholarWorks. For more information, please contact scholarworks@sjsu.edu. 


\title{
Equity, Diversity, and Inclusion Climate Assessment Activities: Development and Strategic Use in Diversity Action Plans
}

\begin{abstract}
This project report describes climate assessment activities in support of the development of a collegelevel diversity, equity, and inclusion (EDI) action plan. Elements of the climate assessment activities are described along with their purpose and rationale for inclusion. Recommendations are made for libraries to design and deploy their own EDI assessment activities with the goal of developing robust action plans supportive of inclusive excellence.
\end{abstract}

\section{Keywords}

equity, diversity, inclusion, climate assessments, action plans, strategic planning, libraries, library education

\section{About Author}

Parinaz Zartoshty, EDI-WG Co-Lead: Parinaz Zartoshty joined CPGE as the Director of International Student \& Scholar Services (ISSS) in May 2018. She has served in similar roles at other institutions of higher education. She entered the field of international education after working for NGOs, including UNICEF and Amnesty International. Parinaz speaks several languages and has worked and studied abroad. She appreciates and encourages a global mindset. She is committed to campus internationalization efforts and strives to create a global ethos at SJSU by fostering a culture of global citizenship and embracing the importance of intercultural competencies, both key factors and contributors to diversity, equity and inclusion efforts as well. Parinaz was born and raised in Tehran, Iran and immigrated to the U.S. at a young age. Her race, class, gender and country of origin have greatly impacted her professional and career path.

Dr. Kristen Rebmann, EDI-WG Co-Lead: Kristen Rebmann is a Professor in the School of Information. She joined the iSchool in 2007 after completing a PhD in Communication from UCSD where she worked as a doctoral researcher at the Laboratory of Comparative Human Cognition. Working within a culturalhistorical theoretical framework, her research involves different forms of technology integration at the community level. A diversity, equity, and inclusion advocate, she served (previously) as the iSchool's Diversity Committee Chair and is the iSchool's current Retention, Tenure, and Promotion Chair. Like many of our students (and reflecting California's rapid demographic changes and diversification), Kristen is a multiracial, multiethnic scholar. She descends from Mexican laborers who left Texas for California in the 1930s and the children of European immigrants who settled in Idaho (also in the 1930s). Lori Vonderach:

Lori Vonderach joined CPGE in December 2019 as an Office Coordinator for the Operations Unit where she supports the Dean and CPGE operations, including helping to support the international students the college serves. Lori has always been a strong advocate for children with special needs (including Autism, Emotional Disturbance and English Language Learners) and worked for the Evergreen School District as a SDC Teacher's Assistant for 12 years. Prior to joining SJSU, Lori worked at Xactly Corporation providing administrative and office support. During this time, she had the privilege of being the direct supervisor for a young man who was part of Best Buddies (a program that secures jobs for people with intellectual and developmental disabilities.) She was also the direct supervisor for four high school students from the Cristo Rey Jesuit High School work study program. This program supports underserved communities in the region. Born and raised in the Bay Area, Lori is the proud parent of three grown children (two SJSU alums) and is inspired by the students with whom she works as an ally and an advocate.

Dr. Vidalino Raatior: Vid Raatior (pronouns: he/him/his) is a proud indigenous member of the Pwaraka and Alengeitaw clans of Chuuk State in the Pacific Island nation of the Federated States of Micronesia 
(FSM). He is a Program Specialist in the Study Abroad \& Away office. Previously, Vid has worked over 20 years in higher education in the fields of international and multicultural education. Born and raised on a small island in Northwest region of Chuuk State, Vid came to the United States for college as an international student eventually earning an Ed.D in Professional Educational Practice from the University of Hawaii at Manoa. His doctoral research focused on strength-based approaches to student support services for Micronesian students attending college in the US. Vid's lived experiences as an immigrant in the US continues to inspire him to advocate for diversity, equity and inclusion.

Erin Kelly-Weber: Erin Kelly-Weber joined CPGE in March 2020 as a Program Specialist in the Study Abroad and Away office. Prior to her tenure at SJSU, she facilitated cultural exchange programs for international high school students during their exchange year in the U.S. She currently serves as a co-chair of Diversity Abroad's Education Abroad Student Support \& Advising Task Force, which develops resources and tools designed to support students across their identities throughout the education abroad continuum. Throughout her decade of working in international education, Erin has studied or worked in 12 countries. Her variety of intercultural professional experiences, in addition to living on the East Coast, Midwest, and West Coast of the U.S., have continued to shape her worldview. Erin is deeply passionate about fostering cross-cultural communication and creating accessible and equitable international education opportunities for every student.

Kimberly Green: Kim Green first began working at International Gateways, formerly named "Studies in American Language", as an instructor in 2000. In her current role as Associate Director, she continues to teach while also overseeing student academic and cultural engagement including curriculum and accreditation review and cultural programming. The former chair of the TESOL International Organization Intensive English Programs Interest Section, she remains active in international discussions regarding learning and culture. A native Californian of multicultural origins, Kim has lived around the U.S. and the world which has fueled her passion for history, culture, and her desire to teach.

\section{Authors}

Dr. Kristen M. Radsliff Rebmann, Parinaz Zartoshty, Kim Green, Erin Kelly-Weber, Dr. Vidalino Raatior, and Lori Vonderach 


\section{Background}

In the fall of 2020, the San Jose State University School of Information partnered with sibling programs in the San Jose State University (SJSU) College of Professional \& Global Education (CPGE) to develop an Equity, Diversity, and Inclusion (EDI) Action Plan for the college. Those programs include: International Student and Scholar Services (ISSS), International Gateways (IG), Study Abroad and Away (SAA), Open University (OU), Summer Session (SS), Department of Applied Data Science (ADS). This project report describes the process of developing an EDI action plan at the unit level-something that many libraries are embarking on. Focus is placed on describing the elements of the EDI climate assessment activities, rationale for their inclusion, and their role in the project's action plan (and potential extension to) similar activities in libraries.

\section{Setting}

CPGE's programs have ties to many communities that provide leadership in the advancement of EDI. Those communities include SJSU, Teaching English to Speakers of Other Languages (TESOL) International Association, the American Library Association (ALA), the Digital Analytics Association (DAA), the National Association of Foreign Student Advisers' (NAFSA) Association of International Educators, the Association for Library \& Information Science Educators (ALISE), Diversity Abroad (2019), Association of International Education Administrators (AIEA), the Institute of International Education (IIE) and the Forum on Education Abroad.

CPGE's mission statement captures the importance of global perspectives in producing successful graduates. A global, intercultural mindset, as well as an understanding and orientation toward EDI is central to the work that CPGE programs do on a daily basis, as reflected in the college's strategic goals, vision, and mission:

In the College of Professional and Global Education at San José State University, we provide access to relevant educational programs that allow individuals to gain knowledge and skills that create a solid foundation for them to be engaged and productive members of a global society. We offer a learning environment that is dynamic and innovative, ensuring that we are responsive to the ever-evolving workforce and industry demands. Our college is the nexus for connecting professionals, institutions, businesses and industries, locally and from around the world, to the knowledge, resources, and talents of Silicon Valley's premier public university. (College of Professional and Global Education, n.d., "Our Mission" section)

Along similar lines, a global ethos is a central component of CPGE's strategic goals to "enhance the overall positive experience of international students and scholars, and achieve awareness and understanding of the value of their presence on campus and in the community" and "foster global competencies in our students and scholars through innovative curricular and cocurricular programming" (College of Professional and Global Education, n.d., "Strategic Goals" section).

\section{Components of the EDI Climate Assessment Activities}

With these college level goals in mind, the Dean and Associate Dean of CPGE, Dr. Ruth Huard and Dr. Sandy Hirsh respectively, established an EDI Working Group to develop several climate assessment activities and draft a subsequent action plan. Our working group developed several activities that occurred via several steps over 2 months, including: 
- values articulation;

- definition of key concepts;

- benchmarking;

- surveys of leadership, staff, and students;

- focus groups; and

- making recommendations.

Included with these activities were the goals of: (a) acknowledging the EDI values of the different fields associated with CPGE; (b) efficiently leveraging practices already being used at other institutions; and (c) giving voice to as many stakeholders as possible via qualitative and quantitative means.

\section{Values Articulation}

As our first step, our team felt it was important to come together as representatives of our many fields and members of the SJSU and CPGE communities to define exactly why EDI is so important to advance. We came up with a vision and intent to advance inclusive excellence at the college level by focusing on the articulation of values. Following Hardiman et al.'s Continuum on Becoming an Anti-Racist Multicultural Organization, we described our ultimate goal to become a "fully inclusive anti-racist multicultural organization in a transformed society" (Hardiman et al., 2007; Crossroads Ministry, 2013, section 6).

We then described that in order to achieve this overarching goal, there must be an action plan in place. Our college and SJSU exists in a socio-cultural milieu of rapid change with emerging EDI-considerations at multiple policy levels. At the same time the federal government is challenging cultural and critical theory-informed training, the State of California is adopting ethnic studies curricular content requirements for undergraduates via Assembly Bill 1460 (Weber, 2020). Assembly Bill 1196 (Gipson, 2020) bans the statewide practice of the chokehold restraints by law enforcement. Title IX is an ever-evolving piece of legislation with recent changes as well. Our sister campus, CSU San Marcos, is championing land acknowledgement procedures via their recent, well-developed toolkit (CSU San Marcos American Indian Studies Department, 2019). As you can see, there are bright spots and positive developments, but the EDI environment is becoming more complex overall and we acknowledged these contextual issues.

Our team then brought in the perspectives of several of our professional organizations including NAFSA Association of International Educators, TESOL Association, and ALISE. NAFSA has defined the importance of EDI structures in education in their 2015 Diversity and Inclusion Statement:

NAFSA honors the richness of human diversity and the essential power of discussion and collaboration across geographic and other boundaries. We affirm that engagement with the range of human beliefs, thoughts, and actions is an important element in global learning that fosters creativity, innovation, and excellence. It strengthens our capacity for constructive engagement to solve the world's complex challenges. (NAFSA, 2015)

Advancing diversity via structures of inclusive excellence and by actively opposing systemic inequities are likewise central and critical components of TESOL International Association's approach to educating the next generation of language professionals, as stated in their 2020 Statement on Racial Injustice and Inequity, "colleagues of color, their families, their friends, and 
their students continue to be harmed by racism, discrimination, and xenophobia. Now is the time to come together and demand that this injustice finally stops" (Cutler, 2020, para. 4).

ALISE's Diversity Statement describes several benefits to advancing diversity:

- Enhances access, attracts and retains diverse membership/personnel.

- Promotes equity and equal opportunity in the organization that lead to better membership satisfaction.

- Facilitates engagement among diverse people that enhances the educational, organizational and scholarly experiences.

- Promotes personal growth and enriches the organization and community.

- Introduces diverse ideas, perspectives, experiences and expertise that lead to improved, informed, creative and innovative problem solving and decision making.

- Opens up new opportunities and modes of discovery, pedagogy and practice.

- Fosters mutual respect by recognizing and valuing differences and commonalities, resulting in cross-cultural understanding.

- Creates an environment in which bias and inequities are not tolerated and compels change.

- Prepares professionals and leaders to work in an expanding, competitive global society.

- Makes for a robust and relevant organization in a diverse society. (ALISE, 2013, "Diversity Benefits" section)

We found the benefits articulated by the different fields not only thought-provoking and ambitious but an important gateway to describing the values of the college that would inform the action plan. As a working group, we were unanimous in our feeling that if stakeholders in CPGE work together to advance inclusive excellence, we will position ourselves strongly to:

1. Promote equity, eliminate bias, and facilitate inclusive engagement among students and colleagues from all backgrounds, including those that are under-represented or underresourced.

2. Introduce innovative perspectives and expertise that promote strategic scholarly developments.

3. Prepare professionals to thrive in complex global contexts.

\section{Extending this activity: What libraries can do to articulate EDI values.}

This process of engaging in values articulation was our first activity, and it was an important one because it forced our team to clearly state vision for the project and describe the reasons why EDI matters so much in a language understood by all the fields and connected to the mission of every university and to CPGE in particular. For libraries, the departments, work areas, academic units can bring the voices of their own professional organizations and priorities of their critical subfields to these discussions. It is important that the values represent the voices of all the professionals in the library.

\section{Definition of Key Concepts}

CPGE did not yet have its own college-level EDI statement or a strategic action plan when the project started and, for this reason, key concepts associated with equity, diversity, and inclusion had not been formally expressed. Our team thought it was important to establish baseline language for use in the action plan and ongoing activities. We decided that the wider university's efforts to begin this process were a good place to begin a discussion about language. SJSU's University- 
wide Commission on Diversity defines six key terms, domains of activity, and strategic indicators that characterize the university's strategy to advance inclusive excellence:

1. Diversity is the active appreciation, engagement, and support of ALL campus members in terms of their backgrounds, identities, and experiences (as constituted by gender, socioeconomic class, political perspective, age, race, ethnicity, religion, sexuality, disability, regional origin, nationality, occupation, language, among others, and the intersection of these aspects). (*This definition emerged from SJSU campus members via focus groups).

2. Inclusive excellence is an institutional commitment to create and sustain a context of diversity through which all members thrive, feel valued, and attain personal and professional success. One specific focus here is to utilize diversity as an educational resource and knowledge domain for students and as a central ingredient for their academic success.

3. Institutional viability and vitality are our capacity to plan, implement and assess a comprehensive diversity approach that aligns with our public mission.

4. Education and scholarship are the diversity content of our courses, faculty engagement with diversity issues and student learning related to diversity.

5. Access and Success are the success (retention, graduation, honors) of our various student populations by level (undergraduate and graduate), demographics (race, gender, ethnicity, income, etc.) and fields (the arts, business, education, science and technology).

6. Campus climate and intergroup relations are the individual and group social interactions among students, faculty, staff and perceptions of institutional commitment to diversity.

Also, influential for our team was University of California, Berkeley's Center for Equity, Gender, and Leadership's Equity Fluent Leaders Glossary of Key Terms (2019). "Equity" and "inclusion" are among the many terms they define, with the goal of building "equity fluency" (UC Berkeley Center for Equity, Gender, and Leadership, 2019).

1. Equity is the process of being treated fairly and impartially (see also gender equity).

2. Inclusion is providing equal opportunity to all people to fully engage themselves in creating an environment and a cultural attitude whereby everyone and every group fits, feels accepted, has value, and is supported by a foundation built on trust and mutual respect. (UC Berkeley Center for Equity, Gender, and Leadership, 2019)

\section{Extending this activity: What libraries can do to define key concepts in EDI.}

The definition of key concepts in EDI enabled us to, collectively, develop a mental model of the ideas and concepts needed to intellectually ground the rest of the data collection-oriented activities. The definitions also enabled us to communicate to CPGE's community members just what these concepts mean when referenced in surveys and focus groups. Along similar lines, library teams working on developing action plans will find it useful to develop their own key definitions for messaging on their websites and in their assessment (e.g., surveys, focus groups, etc.) and action plan authoring activities. Future policies, procedures, and programming will also benefit from these critical definitions, keeping in mind that language will need to be updated in an ongoing fashion.

\section{Benchmarking.}


When our team embarked on the EDI climate assessment activities, we knew that some programs were already making efforts in this area and that uneven levels of activity were something that needed to be identified and responded to. With these differences in mind, we thought that the best way to understand our college's current level of EDI activity would be to benchmark it against an already well-developed program of inclusive excellence associated with another university already on the road to implementing college unit-level structures.

To understand current CPGE EDI-related work practices and division of labor, we engaged in a community scan using a University of Michigan-inspired "EDI Check-up" document (Diversity, Equity \& Inclusion: University of Michigan, n.d.). The community scan, using the activity and check-up document, was inspired by the University of Michigan's dimensions of EDI activity that they identified as relevant to the EDI professionals currently working at the college/unit level (Grim et al, 2019.) These dimensions of EDI activity include activities and practices in the areas of Leadership, Programming, Faculty/Staff Engagement, and Student Engagement. With these practices in mind, we developed a baseline understanding of what CPGE is currently doing in these areas by recording what we found out (i.e., through communications with colleagues and study of CPGE documentation) in a check-up document in GoogleDocs.

\section{Extending this activity: How libraries can use benchmarking.}

We suspected that there was a general unevenness in the degree to which the individual programs and academic units (e.g., IG, ISSS, SAA, ADS, and iSchool) had developed their own EDI structures and the benchmarking activities confirmed it. Activities associated with the community scan also made visible that there were several gaps in CPGE's EDI activities and enabled the team to address several of these items strategically in subsequent surveys and focus groups.

Along similar lines to our efforts to engage in benchmarking via community scanning activities, libraries can look outward to find other institutions that are further along in their own journeys toward inclusive excellence. Published case studies, organizational project reports, and professional communications at conferences are all viable outlets for libraries to find leaders in the field. Use their experiences as rubrics as you scan and assess your library's current level of activity. As you look toward developing other assessment tools and activities, such as surveys and focus groups, consider what you have learned in your library's "check-up" first. Your surveys and focus group questions will be more strategic and result in more useful information.

\section{Surveys of Leadership, Staff, and Students}

Our survey efforts consisted of instruments developed in Qualtrics and as a Google Form. The differences had to do with variations in expertise among team members. The CPGE Leadership Survey: Equity, Diversity and Inclusion (EDI) online survey (in Google) was administered to all unit heads of the departments at CPGE and consisted of two sections: (a) an overview section to determine each department's alignment (or lack thereof) with CPGE's vision, mission and strategic goals; and (b) a review of existing activities in the areas of leadership, programming, and engagement with faculty, staff, and students. The questions were deliberately open-ended in an effort to help us gauge the unit heads' abilities to articulate ways in which they are leading their department in the areas of EDI activities.

The faculty/staff/administrator survey, designed in Qualtrics, was sent out to all full-time employees (staff and faculty) of CPGE (approximately 90), part-time lecturers and student assistants, in order to gauge their understanding and perspectives on EDI issues.

Our team developed two student surveys in Qualtrics, with one containing specialized questions for Study Abroad and Away (SAA) students and the other primed to students in 
International Student and Scholar Services (ISSS), International Gateways (IG), the Department of Applied Data Science (ADS), and the School of Information (iSchool). We analyzed 236 responses from the survey sent to all students in iSchool, ADS, IG, and ISSS (over 1000 students total).

\section{Extending this activity: What libraries can use surveys as part of EDI assessments.}

The surveys worked well in that they provided a 360 degree perspective on community members' experiences of equity, diversity, and inclusion issues in the unit. Producing quantitative datasets which tied feedback to participant characteristics such as major, work function, ethnicity, and dimensions of diversity represented (to name a few). Open-ended questions resulted in rich quotes about EDI areas of concern and desired programming, courses, and training opportunities.

Libraries might take a similar approach to understanding staff perspectives on EDI issues, student experiences of the library and its services, and goals/activities associated with members of the leadership team. Analyzed together, these datasets will provide the quantitative evidence and rich qualitative portraits of community members needed to support EDI recommendations and future action plans.

\section{Focus Groups}

Extending our efforts to obtain faculty/staff feedback on diversity issues, we scheduled three sets of virtual focus groups via Zoom web-based conferencing. Workgroup members agreed upon five focus group questions, which were administered in three focus groups of 14 participants, led by two team members each. The two workgroup members responsible for each respective focus group then reviewed their Zoom session's recordings, transcripts, and comments. One of the focus group leads integrated Poll Everywhere online activities into their focus groups and collected related responses.

\section{Extending this activity: How libraries can use surveys as part of EDI assessments.}

The strength of the focus groups was that once a question was asked, it was possible, like a town hall meeting, to have a conversation about answers, opinions, and problem solving. Brainstorming and "raising concerns" was part and parcel of the focus groups which added another set of findings to triangulate around as recommendations for action were considered. Libraries have a rich history of deploying focus groups to understand library usage and patron opinions on collections, programs, and services. Re-imaging focus groups to understand community needs around EDI issues is one simple step libraries can take to develop more evidence in support of any initiatives promoting inclusive excellence in their organizations. Technologies like Zoom make virtual focus groups possible while applications like Poll Everywhere create opportunities for gamification in responses and collective sharing/responding to questions in a rich, engaging environment.

\section{Making Recommendations}

We used the climate assessment activities relating to values articulation, defining key concepts, benchmarking, surveys, and focus groups to develop a diversity action plan. Structured as a strategic planning document includes five EDI Strategic Directions with related goals/objectives that are articulated as recommendations for action by specific dates within the college. We articulated several key performance indicators (KPIs) associated with each recommended objective to chart progress on stated goals. The KPIs have one or more individuals/groups tasked with each item and a timeline (e.g., due date or schedule such as annually or ongoing) for completion. In our particular case, the EDI strategic directions emerged in the realms of 
leadership, programming and assessment, faculty and staff affairs, student affairs, new directions in EDI. The "new directions" strategic direction attempted to capture emerging issues in EDI that did not emerge from our dataset but are known issues to team members.

\section{Extending this activity: How libraries can make recommendations as part of an EDI action plan?}

When our team structured the action plan with KPIs designed to chart progress on objectives flowing from several strategic directions, it was with the intent to prime the entire deliverable for inclusion in strategic planning, program planning, and accreditation processes. Along these lines, the action plan is poised for easy insertion into ongoing program and college level in the hopes that equity, diversity, and inclusion concerns will become a normalized part of governance and program trajectories. Libraries should likewise seize the opportunity to structure their recommendations as strategic planning documents. Such efforts will support the sustainability of EDI efforts, thereby increasing the likelihood that proposed action plans are adopted.

\section{Conclusion}

Surprisingly, our team only had two months, from charge to due date, to execute our plans. Despite the short time period allotted for the delivery of this report, we were able to utilize a mixed methods approach, resulting in the analyses of several datasets that justified a hearty compilation of recommendations. Importantly, we were successful due to the strong support we received from our leadership team, colleagues, and students. Our project could have been improved if we had time to file a protocol with SJSU's institutional review board (IRB), enabling dissemination of some of the rich data we cultivated. Libraries would do well to insert IRB coverage into their EDI assessment activities to support scholarly communication to the field. Ultimately, we feel strongly that the current analyses and recommendations are merely a starting point and look forward to the opportunity to deploy additional and ongoing college-level assessments as CPGE adopts new EDI structures in the future.

\section{References}

ALISE. (2013). ALISE diversity statement. https://www.alise.org/alise---alise-diversitystatement\#: :text=ALISE's\%20commitment\%20to\%20diversity\%20is,)\%20and\%20compete ncies\%20(how).

College of Professional and Global Education. (n.d.). Our mission. https://www.sjsu.edu/cies/aboutus/mission/index.html

Crossroads Ministry. (2013). Continuum on becoming an anti-racist multicultural organization [AESA PDF]. https://www.aesa.us/conferences/2013_ac_presentations/Continuum_AntiRacist.pdf?fbclid=I wAR0nhgykWXZGwYuZKDtWLuWDcked2ItIUGfLGRtX7SW3USdL2EP218IWZV8

CSU San Marcos American Indian Studies Department. (2019). Land acknowledgement: So you're on California Indian land, now what? [A Toolkit.] https://www.csusm.edu/cicsc/land.pdf.

Cutler, D. (2020). TESOL statement on racial injustice and inequality [TESOL International Association]. https://www.tesol.org/news-landing-page/2020/06/01/tesol-statement-on-racialinjustice-and-inequality

Diversity, Equity \& Inclusion: University of Michigan. (n.d.). Data \& reports. https://diversity.umich.edu/data-reports/ 
Diversity Abroad. (2019). Global equity \& inclusion guidelines. https://www.diversitynetwork.org/page/AIDERoadmap.

Gipson, M. (2020). Peace officers: use of force [CA A.B. 1196]. https://leginfo.legislature.ca.gov/faces/billTextClient.xhtml?bill id=201920200AB1196

Grim, J. K., Sánchez-Parkinson, L., Ting, M., \& Chavous, T. (2019). The experiences of academic diversity officers at the University of Michigan. NCID Currents, 1(1). http://dx.doi.org/10.3998/currents.17387731.0001.111

Hardiman, R., Jackson, B., \& Griffin, P. (2007). Conceptual foundations for social justice education. In M. Adams, L. A. Bell, \& P. Griffin (Eds.), Teaching for diversity and social justice (2nd ed., pp. 35-66). Routledge.

NAFSA. (2015). NAFSA diversity and inclusion statement. https://www.nafsa.org/about/aboutnafsa/nafsa-diversity-and-inclusionstatement\#: :text=Approved\%20by \%20the \%20Board\%20of\%20Directors\%2C\%20Decembe r $\% 205 \% 2 \mathrm{C} \% 202015 \&$ text=NAFSA $\% 20$ affirms $\% 20 \mathrm{its} \% 20 \mathrm{commitment} \% 20$ to, and $\% 20$ learni ng\%20from\%20diverse\%20perspectives

UC Berkeley Center for Equity, Gender, and Leadership (Ed.). (2019, June). Equity fluent leader glossary. Retrieved November 20, 2020, from https://drive.google.com/file/d/1uxXow_se_fliNbZlftRz2H7Jw161Mp7G/view

Weber, S. (2020). California state university: graduation requirement: ethnic studies [CA A.B. 1460]. https://leginfo.legislature.ca.gov/faces/billTextClient.xhtml?bill_id=201920200AB1460

\section{Acknowledgements}

Acknowledgment is extended to San Jose State University's College of Professional \& Global Education and its associated programs and academic units for their continued support of the project written about in this report. 